\title{
Reduced Activity Dimension
}

National Cancer Institute

\section{Source}

National Cancer Institute. Reduced Activity Dimension. NCI Thesaurus. Code C132287.

A dimension of reduced activity in the Multidimensional Fatigue Inventory. 